\title{
The impact of social engagement on
} health-related quality of life and depressive symptoms in old age - evidence from a multicenter prospective cohort study in Germany

André Hajek ${ }^{1 *}\left(\mathbb{D}\right.$, Christian Brettschneider ${ }^{1}$, Tina Mallon², Annette Ernst ${ }^{2}$, Silke Mamone ${ }^{3}$, Birgitt Wiese ${ }^{3}$, Siegfried Weyerer ${ }^{4}$, Jochen Werle ${ }^{4}$, Michael Pentzek ${ }^{5}$, Angela Fuchs ${ }^{5}$, Janine Stein ${ }^{6}$, Tobias Luck ${ }^{6}$, Horst Bickel ${ }^{7}$, Dagmar Weeg ${ }^{7}$, Michael Wagner ${ }^{8,9}$, Kathrin Heser ${ }^{8}$, Wolfgang Maier ${ }^{8,9}$, Martin Scherer $^{2}$, Steffi G. Riedel-Heller ${ }^{6 \dagger}$, Hans-Helmut König ${ }^{1 \dagger}$, for the AgeCoDe Study Group

\begin{abstract}
Background: Thus far, only a few longitudinal studies investigated the impact of social engagement on health-related quality of life (HRQoL) and depressive symptoms in old age. Therefore, we aimed to examine the impact of social engagement on HRQOL and depressive symptoms in late life.

Methods: Individuals aged 75 years and over at baseline were interviewed every 1.5 years in a multicenter prospective cohort study in Germany. While HRQoL was quantified by using the Visual Analogue Scale (EQ VAS) of the EQ-5D instrument, depressive symptoms was assessed by using the Geriatric Depression Scale (GDS). Individuals reported the frequency ("never" to "every day") of social engagement (e.g., engagement in the church, as a volunteer, in a party, or in a club) in the last four weeks. Fixed effects regressions were used to estimate the effect of social engagement on the outcome variables.

Results: After adjusting for age, marital status, functional status and chronic diseases, fixed effects regressions revealed that the onset of social engagement markedly increased HRQOL and considerably decreased depressive symptoms in the total sample and in women, but not men.

Conclusions: Our findings corroborate the relevance of social engagement for HRQOL and depressive symptoms in old age. Encouraging the individuals to start, maintain and expand social engagement in late life might help to maintain and improve HRQOL and decrease depressive symptoms.
\end{abstract}

Keywords: Depressive symptoms, EQ-VAS, Geriatric Depression Scale, Health-related quality of life, Old age

\footnotetext{
*Correspondence: a.hajek@uke.de

${ }^{\dagger}$ Equal contributors

${ }^{1}$ Department of Health Economics and Health Services Research, Hamburg

Center for Health Economics, University Medical Center Hamburg-Eppendorf,

Hamburg, Germany

Full list of author information is available at the end of the article
} 


\section{Background}

Social aspects of life can be divided into three components: support, networks and engagement [1]. While social support can be defined as the access to relationships that meet a person's basic social needs through environmental supplies of social support [2], the use of social network can be defined as "an analytic concept, used to describe the structure of linkages between individuals or groups of individuals. Such networks have a variety of functions of which the provision of social support is but one" [3].

Social engagement, reflects an active engagement implying that individuals choose to participate $[4,5]$. In $2009,20 \%$ of the individuals aged 75 and above were socially engaged in Germany. These individuals were often engaged in activities connected to a church or a religion (33\%), in the social (e.g. charity or another aid agency)/ health sector (e.g. assisting with the nursing of sick people) (34\%) or in other activities (e.g. sport club, theatre group, club for older people) (57\%). Moreover, $20 \%$ of these socially engaged individuals were willing to expand their engagement. Furthermore, $18 \%$ of the individuals who were not socially engaged in 2009 were willing to start voluntary activities (4\% = "yes"; $14 \%$ = "maybe"). Additionally, it was extremely important for individuals in late life to help other people in their voluntary activities [6]. Due to these reasons and as it is expected that the number and proportion of individuals in old age will considerably increase in the next decades, there is a huge potential for older people getting socially involved, e.g. in the issue of refugees. Particularly this issue is projected to be a challenge to Germany in upcoming decades, underlining the importance of social engagement in old age in the future.

Social engagement is also of particular relevance in old age since many events occur in old age such as retirement, the empty nest phenomenon or the death of the spouse or close friends. Moreover, it is worth emphasizing that the absence of social engagement is associated with main adverse health outcomes such as cognitive decline [7] or mortality [1].

However, the impact social engagement has on other main health outcomes including health-related quality of life (HRQoL) and depressive symptoms longitudinally is largely unknown. While HRQoL is a multidimensional construct, focusing on how an illness and its treatment affect physical, psychological, and social aspects of life, depressive symptoms include our psychological, emotional and social well-being [8].

Several cross-sectional studies found positive associations between social engagement and HRQoL as well as less depressive symptoms in old age across cultures $[9,10]$. However, these studies fail to identify causal mechanisms. While some longitudinal studies exist investigating the impact of social variables on HRQoL and depressive symptoms in old age [11-13], most of them did not use panel data methods. Consequently, the causal association between social engagement and HRQoL as well as depressive symptoms is not well understood.

Moreover, most of the existing longitudinal studies focus on social support and social networks, including [14] informal caregiving [15], whereas only a few studies $[12,13,16,17]$ investigated the association between engagement and HRQoL as well as depressive symptoms. For example, Schwingel et al. [13] found that at baseline and 2-year follow up volunteering retirees had less depressive symptoms than non-volunteering retirees. Moreover, Hong et al. [16] found that volunteering was associated with longitudinal changes in depression (single item). Longitudinal studies investigating the impact of social engagement on HRQoL and depressive symptoms in late life are missing for Germany.

Therefore, to close this research gap, we aimed at investigating the impact of social engagement on HRQoL and depressive symptoms in late life. It is assumed that social engagement might provide a sense of competence and feelings of usefulness [18]. Moreover, these factors are associated with sense of control and mastery [19]. These characteristics are in turn related to HRQoL and depressive symptoms [20].

To address this research question adequately, data were derived from a multicenter prospective cohort study in Germany. Moreover, fixed effects (FE) regressions were used (i) to produce consistent estimates (time-constant unobserved factors were taken into account) and (ii) to gain insights into the causal relationship between social engagement and the outcome variables. More specifically, unlike other widely used panel data methods, FE regressions provide consistent estimates even if time-constant unobserved factors (such as genetic disposition) are correlated with the predictors - which is often the case in HRQoL and depressive symptoms research.

This knowledge about the longitudinal predictors is vital as the results of our study might highlight the importance of developing strategies to encourage social engagement in late life. This might help to preserve and increase HRQoL and decrease depressive symptoms in old age.

\section{Methods \\ Sample}

Data from the German Study on Ageing, Cognition and Dementia in Primary Care Patients (AgeCoDe) were used. The AgeCoDe study is a multicenter (Leipzig, Hamburg, Dusseldorf, Mannheim, Bonn and Munich) prospective cohort study. In 2003/2004 (baseline) individuals were recruited via General Practitioners' (GP) offices. From that point on, individuals were interviewed by trained staff every 1.5 years (follow-up (FU) wave 5 taking place in 
2011/2012). Inclusion criteria at baseline were: (i) $\geq 75$ years, (ii) absence of dementia and (iii) at least one contact with the GP in the last 12 months. Exclusion criteria at baseline were: insufficient knowledge of the German language, consultations only via home visits, residence in a nursing home $(\mathrm{NH})$, severe illness the GP would deem fatal within 3 months, deafness, blindness, lack of ability to provide informed consent and being an irregular patient of the participating practice. Luck et al. [21] published more details concerning the sampling frame. The study has been approved by the local ethics boards of all participating centers and written informed consent was obtained from all patients.

In our main analysis, four waves (FU wave 2 to $\mathrm{FU}$ wave 5 , with $\mathrm{n}_{\mathrm{FU}}$ Wave2 $=2364$ ) were used because HRQoL and comorbidity was included from FU wave 2 onwards. Main reasons for lack of follow-up data were refused participation and death.

\section{Health-related quality of life}

By using the Visual Analogue Scale (EQ VAS) of the EQ-5D instrument [22], HRQoL was assessed. The scale ranges from 0 (worst imaginable health state) to 100 (best imaginable health state). This scale is frequently used to quantify self-reported health and has good psychometric properties in late life [23].

\section{Depressive symptoms}

The Geriatric Depression Scale (GDS [24]) was used to quantify depressive symptoms, ranging from 0 (no depressive symptoms) to 15 (severe depression). The GDS also has good psychometric properties [25].

\section{Independent variables}

Individuals reported the frequency ("every day", "several times a week", "once a week" and "never") for social engagement in the last four weeks (e.g. tutoring, engagement in the church, as a volunteer, in a party, in an old-age home, or in a club). As for sociodemographic variables, age, sex, education (CASMIN classification [26]), with primary, secondary and tertiary education), living situation (Ref.: living alone in private household; others (with spouse/partner, with other relatives, nursing home, assisted living, retirement home, other)) and marital status (Ref.: married; others (single, widowed, divorced)) were used. Education and living situation were solely used for descriptive purposes.

Functional impairment was quantified by the Lawton and Brody Instrumental Activities of Daily Living scale (IADL, $0=$ worst score, $8=$ best score) [27]. The comorbidity was quantified by the presence of 28 chronic conditions (assessed by the GP) such as diabetes, or obesity. If a chronic condition was present, the GP rated the severity from 1 (= mild) to 4 (= severe). By summing the severity rating for chronic conditions as present, a weighted count comorbidity score was computed to take the severity of the chronic diseases into consideration.

\section{Statistical analysis}

In order to estimate the effects of time-dependent regressors on our outcome variables (HRQoL and depressive symptoms), linear fixed effects (FE) regressions were used. Contrarily to FE regressions, random effects (RE) regressions are inconsistent if time-constant unobserved variables such as optimism, personality or genetic disposition are correlated with the regressors [28]. Sargan-Hansen tests (which is a Hausman test with cluster-robust standard errors) indicated that FE regressions are the method of choice. This means that FE regressions provide consistent estimates even if time-constant factors are correlated with the predictors (under the assumption of strict exogeneity). The FE-estimator is also called 'within-estimator' as solely intraindividual changes over time are exploited. Furthermore, it is worth noting that gender-specific regressions were computed since social engagement varies between women and men [29, 30]. The level of significance was set to $5 \%$. Statistical analyses were performed using Stata 14 (Stata Corp., College Station, Texas). Robust standard errors that cluster errors at the individual level were computed. It is worth noting that the Stata command for FE regression analysis include subjects with only one observation in calculating the number of observations since these subjects provide information about, e.g., the variance components, the constant, the between $R^{2}$, and the overall $R^{2}$. Nevertheless, it does not affect the beta-coefficients as well as the standard errors.

\section{Results}

\section{Descriptive analysis}

At FU wave 2 , mean age was 82.5 years ( \pm 3.4 years) (see Table 1$)$. The majority was female $(65.8 \%)$, had a low education (60.5\%), were not married (61.4\%) and was living alone in private household (51.4\%). The mean comorbidity (weighted count score) was $4.5( \pm 3.8)$, IADL was 6.8 $( \pm 1.7)$, mean EQ-VAS was $65.5( \pm 17.9)$ and mean GDS was $2.5( \pm 2.5) .14 .0 \%$ of the individuals were socially engaged at least once a week. After 4.5 years (FU wave 5), the proportion of unmarried individuals significantly increased as many spouses died. Other sociodemographic variables remained nearly constant. Additionally, while functional impairment increased, the mean comorbidity score decreased.

Furthermore, it is worth mentioning that between FU wave 2 and FU wave 5165 individuals started social engagement in this longitudinal study (i.e. intraindividual changes from 'no social engagement' to 'social engagement' (once a week, several times a week or daily)). 
Table 1 Descriptive Statistics over Time (Follow-Up Waves 2-5)

\begin{tabular}{|c|c|c|c|c|}
\hline Variables & $\begin{array}{l}\text { Follow-Up Wave } 2 \\
(n=2364)\end{array}$ & $\begin{array}{l}\text { Follow-Up Wave } 3 \\
(n=1827)\end{array}$ & $\begin{array}{l}\text { Follow-Up Wave } 4 \\
(n=1453)\end{array}$ & $\begin{array}{l}\text { Follow-Up Wave } 5 \\
(n=1174)\end{array}$ \\
\hline Age: Mean (SD) & $82.5(3.4)$ & $83.9(3.3)$ & $85.2(3.2)$ & $86.7(3.0)$ \\
\hline Female: N (\%) & $1556(65.8)$ & $1203(65.9)$ & $963(66.3)$ & $790(67.3)$ \\
\hline \multicolumn{5}{|l|}{ Education: N (\%) } \\
\hline Low Education & $1431(60.5)$ & $1092(59.8)$ & $838(57.7)$ & $665(56.6)$ \\
\hline Middle Education & $656(27.8)$ & $517(28.3)$ & $438(30.1)$ & $356(30.3)$ \\
\hline High Education & $277(11.7)$ & $218(11.9)$ & $177(12.2)$ & $153(13.0)$ \\
\hline Unmarried: N (\%) & 1449 (61.4) & $1193(65.4)$ & $966(66.5)$ & $832(70.9)$ \\
\hline Living alone in private household: N (\%) & $1216(51.4)$ & $959(52.5)$ & $773(53.2)$ & $606(51.6)$ \\
\hline Comorbidity (Weighted count score): Mean (SD) & $4.5(3.8)$ & $4.4(3.7)$ & $4.5(3.8)$ & $3.9(3.7)$ \\
\hline Functional status (IADL): Mean (SD) & $6.8(1.7)$ & $6.8(1.7)$ & $6.6(1.8)$ & $6.3(2.0)$ \\
\hline HRQoL (EQ-VAS): Mean (SD) & $65.5(17.9)$ & $64.8(17.5)$ & $64.3(17.5)$ & $62.9(18.9)$ \\
\hline $\begin{array}{l}\text { Depressive symptoms (Geriatric Depression } \\
\text { Scale): Mean (SD) }\end{array}$ & $2.5(2.5)$ & $2.4(2.3)$ & $2.5(2.4)$ & $2.7(2.5)$ \\
\hline \multicolumn{5}{|l|}{ Social engagement: N (\%) } \\
\hline No social engagement & $2031(86.0)$ & $1662(91.4)$ & $1318(91.2)$ & 1090 (93.6) \\
\hline Once a week & $175(7.4)$ & $85(4.7)$ & $69(4.8)$ & $41(3.5)$ \\
\hline Several times a week & $116(4.9)$ & $54(3.0)$ & $40(2.8)$ & $25(2.1)$ \\
\hline Daily social engagement & $39(1.7)$ & $16(0.9)$ & $17(1.2)$ & $8(0.7)$ \\
\hline
\end{tabular}

Contrarily, for example, 112 individuals changed from social engagement several times a week to no social engagement) (further details to intraindividual changes are available upon request).

\section{Regression analysis}

Adjusting for age, marital status, functional status (IADL) and chronic diseases, FE regressions revealed that the onset of social engagement several times a week (Ref.: no social engagement) markedly increased HRQoL in the total sample $(\beta=4.1, p<.001)$ and in women $(\beta=6.2$, $p<.001$ ) (see Table 2). In other words: The loss of social engagement substantially reduced HRQoL in the total sample and in women. It is worth mentioning that changes in social engagement did not affect HRQoL in men (with significant interaction term: gender $\mathrm{x}$ onset of social engagement several times a week, $p<.05$ ).

Moreover, FE regressions revealed that the onset of social engagement decreased depressive sympoms in the total sample (onset of social engagement once a week: $\beta=-.3, p<.01$; onset of social engagement several times a week: $\beta=-.3, p<.01$ ) and in women (onset of social engagement once a week: $\beta=-.4, p<.01$; onset of social engagement several times a week: $\beta=-.3, p<.05$ ) (see Table 3). Even though changes in social engagement did not affect depressive symptoms in men, the interaction terms (gender $\mathrm{x}$ social engagement) did not achieve statistical significance.

\section{Discussion}

This study investigated the impact of social engagement (engagement in the church, as a volunteer, in a party, or in a club) on HRQoL and depressive symptoms in late life in Germany. After adjusting for main control variables such as age, functional status and chronic diseases, longitudinal regressions showed that the onset of social engagement markedly increased HRQoL as well as considerably decreased depressive symptoms in the total sample and in women, but not men.

Several cross-sectional studies showed that social engagement is positively associated with HRQoL and less depressive symptoms in late life. Moreover, longitudinal studies found significant associations between social engagement and HRQoL as well as depressive symptoms in old age. For instance, using the Singapore longitudinal ageing studies, Schwingel [13] showed that volunteering retirees have less depressive symptoms compared with non-volunteering retirees at baseline and 2-year followup. Additionally, Menec [12] investigated the association between respective activities at baseline and subsequent outcomes (well-being, function and mortality). By using logistic regressions, Menec [12] found that volunteer work at baseline (1990) was predictive of better function 6 years later. Data were derived from the Aging in Manitoba (AIM) Study which is a long-running representative sample of older adults living in Manitoba (Canada). Furthermore, by using latent class growth curve models, Hong et al. [16] showed that volunteering was associated 
Table 2 Predictors of HRQoL (EQ-VAS): Results of fixed effects regression (Follow-up waves 2-5)

\begin{tabular}{|c|c|c|c|c|}
\hline \multirow[t]{2}{*}{ Independent variables } & (1) & $(2)$ & (3) & (4) \\
\hline & HRQOL - Total sample & HRQOL - Women & HRQOL - Men & HRQOL - Interaction \\
\hline \multirow[t]{2}{*}{ Increasing age } & $-1.049^{* * *}$ & $-1.057^{* * *}$ & $-1.082^{* * *}$ & $-1.061^{* * *}$ \\
\hline & $(0.106)$ & $(0.144)$ & $(0.172)$ & $(0.106)$ \\
\hline \multirow[t]{2}{*}{ Loss of spouse } & 1.882 & 0.875 & $3.591^{*}$ & 1.961 \\
\hline & $(1.195)$ & $(1.606)$ & $(1.752)$ & $(1.195)$ \\
\hline \multirow{2}{*}{$\begin{array}{l}\text { Onset of social engagement once a week } \\
\text { (Ref.: No social engagement) }\end{array}$} & 0.188 & -0.244 & 0.989 & -0.232 \\
\hline & $(0.954)$ & $(1.217)$ & $(1.501)$ & $(1.216)$ \\
\hline \multirow[t]{2}{*}{ Onset of social engagement several times a week } & $4.056^{* * *}$ & $6.150 * * *$ & 0.235 & $6.165^{* * *}$ \\
\hline & $(1.220)$ & $(1.483)$ & $(2.031)$ & $(1.480)$ \\
\hline \multirow[t]{2}{*}{ Onset of daily social engagement } & 1.095 & -0.919 & 4.150 & -0.853 \\
\hline & $(1.864)$ & $(2.312)$ & $(3.071)$ & $(2.305)$ \\
\hline \multirow{2}{*}{$\begin{array}{l}\text { Interaction: Gender x onset of social engagement } \\
\text { once a week }\end{array}$} & & & & 1.186 \\
\hline & & & & $(1.924)$ \\
\hline \multirow{2}{*}{$\begin{array}{l}\text { Gender } x \text { onset of social engagement several } \\
\text { times a week }\end{array}$} & & & & $-5.929^{*}$ \\
\hline & & & & $(2.493)$ \\
\hline \multirow[t]{2}{*}{ Interaction: Gender x onset of daily social engagement } & & & & 4.775 \\
\hline & & & & $(3.793)$ \\
\hline \multirow[t]{2}{*}{ Decreasing functional impairment (IADL) } & $0.591^{* *}$ & $0.556^{*}$ & $0.606^{*}$ & $0.581^{* *}$ \\
\hline & $(0.186)$ & $(0.274)$ & $(0.260)$ & $(0.186)$ \\
\hline \multirow[t]{2}{*}{ Comorbidity (Weighted score) } & -0.121 & -0.120 & -0.113 & -0.116 \\
\hline & $(0.0964)$ & $(0.129)$ & $(0.145)$ & $(0.0965)$ \\
\hline \multirow[t]{2}{*}{ Constant } & $148.0^{* * *}$ & $148.3^{* * *}$ & $153.1^{* * *}$ & $149.0^{* * *}$ \\
\hline & $(9.104)$ & $(12.95)$ & $(14.21)$ & $(9.088)$ \\
\hline Observations & 6816 & 4511 & 2305 & 6816 \\
\hline$R^{2}$ & 0.036 & 0.039 & 0.035 & 0.038 \\
\hline Number of Individuals & 2381 & 1565 & 816 & 2381 \\
\hline
\end{tabular}

Comments: Beta-Coefficients were reported; Cluster-robust standard errors in parentheses. ${ }^{* * *} p<0.001,{ }^{* *} p<0.01,{ }^{*} p<0.05,+p<0.10$. Observations with missing values were dropped (listwise deletion)

with changes in depressive symptoms in old age. They used three waves (1994-2000) from the Longitudinal Study on Aging (LSOA) II which is a nationally representative sample of community-dwelling individuals aged 70 years and above. However, they used a single item (how often they felt sad or depressed in the past 12 months using a 4-point scale) to quantify depression. Furthermore, by using the generalized estimating equations method, Morrow-Howell et al. [17] found that older adults who volunteer report higher levels of selfrated health (1-5, excellent to poor) and less depressive symptoms (modified Center for Epidemiological Studies Depression Scale (CES-D)). They used three waves (1986, 1989, 1994) from the Americans' Changing Lives (ACL) Study. The ACL Study is a panel survey (in wave 1,1669 older adults were included in the analysis) with an oversampling of people aged 60 and above.

Our study adds to the growing body of evidence that social engagement in late life affects HRQoL and depressive symptoms. By focusing solely on intraindividual changes - which is very important in HRQoL and depressive symptoms research - our findings extend previous studies. Thus, insights into the causal relationship can be derived. Our key findings - social engagement affects HRQoL and depressive symptoms - might be explained by a sense of competence and feelings of usefulness that are accompanied by social engagement. These variables are related to mastery and a sense of control: Factors that are in turn associated with depressive symptoms and HRQoL.

Like other studies [17], data suggest a nonlinear relationship between frequency of volunteering and our health outcomes, indicating that there might be an optimal frequency of social engagement in late life. From a public health perspective, it is worth emphasizing that the onset of weekly social engagement already decreased depressive symptoms. Thus, even modest amounts of social engagement might be beneficial. This information can 
Table 3 Predictors of depressive symptoms (GDS): Results of fixed effects regression (Follow-up waves 2-5)

\begin{tabular}{|c|c|c|c|c|}
\hline \multirow[t]{2}{*}{ Independent variables } & (1) & $(2)$ & (3) & (4) \\
\hline & $\begin{array}{l}\text { Depressive symptoms - } \\
\text { Total sample }\end{array}$ & Depressive symptoms - Women & Depressive symptoms - Men & $\begin{array}{l}\text { Depressive symptoms - } \\
\text { Interaction }\end{array}$ \\
\hline \multirow[t]{2}{*}{ Increasing age } & $0.0711^{* * *}$ & $0.0416^{*}$ & $0.0978^{* * *}$ & $0.0710^{* * *}$ \\
\hline & $(0.0118)$ & $(0.0164)$ & $(0.0184)$ & $(0.0119)$ \\
\hline \multirow[t]{2}{*}{ Loss of spouse } & 0.101 & 0.128 & 0.0557 & 0.103 \\
\hline & $(0.164)$ & $(0.219)$ & $(0.243)$ & $(0.164)$ \\
\hline \multirow{2}{*}{$\begin{array}{l}\text { Onset of social engagement once a } \\
\text { week (Ref.: No social engagement) }\end{array}$} & $-0.346^{* *}$ & $-0.389^{* *}$ & $-0.250+$ & $-0.381^{* *}$ \\
\hline & $(0.106)$ & $(0.144)$ & $(0.132)$ & $(0.145)$ \\
\hline \multirow{2}{*}{$\begin{array}{l}\text { Onset of social engagement several } \\
\text { times a week }\end{array}$} & $-0.274^{* *}$ & $-0.307^{*}$ & -0.175 & $-0.307^{*}$ \\
\hline & $(0.106)$ & $(0.128)$ & $(0.186)$ & $(0.127)$ \\
\hline \multirow[t]{2}{*}{ Onset of daily social engagement } & -0.219 & -0.329 & -0.100 & -0.310 \\
\hline & $(0.209)$ & $(0.305)$ & $(0.266)$ & $(0.302)$ \\
\hline \multirow{2}{*}{$\begin{array}{l}\text { Interaction: Gender x onset of social } \\
\text { engagement once a week }\end{array}$} & & & & 0.109 \\
\hline & & & & $(0.198)$ \\
\hline \multirow{2}{*}{$\begin{array}{l}\text { Gender } x \text { onset of social engagement } \\
\text { several times a week }\end{array}$} & & & & 0.0921 \\
\hline & & & & $(0.224)$ \\
\hline \multirow{2}{*}{$\begin{array}{l}\text { Interaction: Gender x onset of daily } \\
\text { social engagement }\end{array}$} & & & & 0.225 \\
\hline & & & & $(0.407)$ \\
\hline \multirow{2}{*}{$\begin{array}{l}\text { Decreasing functional impairment } \\
\text { (IADL) }\end{array}$} & $-0.155^{* * *}$ & $-0.205^{* * *}$ & $-0.0916^{* *}$ & $-0.155^{* * *}$ \\
\hline & $(0.0238)$ & $(0.0350)$ & $(0.0287)$ & $(0.0239)$ \\
\hline \multirow[t]{2}{*}{ Comorbidity (Weighted score) } & $0.0310^{* *}$ & $0.0345^{*}$ & 0.0215 & $0.0310^{* *}$ \\
\hline & $(0.0102)$ & $(0.0139)$ & $(0.0141)$ & $(0.0102)$ \\
\hline \multirow[t]{2}{*}{ Constant } & $-2.600^{*}$ & 0.399 & $-5.519^{* * *}$ & $-2.601^{*}$ \\
\hline & $(1.008)$ & $(1.471)$ & $(1.516)$ & $(1.013)$ \\
\hline Observations & 7010 & 4658 & 2352 & 7010 \\
\hline$R^{2}$ & 0.046 & 0.054 & 0.035 & 0.046 \\
\hline Number of Individuals & 2391 & 1572 & 819 & 2391 \\
\hline
\end{tabular}

Comments: Beta-Coefficients were reported; Cluster-robust standard errors in parentheses. ${ }^{* * *} p<0.001,{ }^{* *} p<0.01,{ }^{*} p<0.05,+p<0.10$. Observations with missing values were dropped (listwise deletion)

be used to let voluntary activities sound more attractive. However, more research is required on this issue as we did not know the exact hours per week socially engaged.

The non-significant impact of social engagement on HRQoL and depressive symptoms among men might be explained by the types of activities examined in the present study. More specifically, activities that are more informal might be beneficial to men. However, this should be clarified in future studies.

This is the first longitudinal study examining the impact of social engagement on HRQoL and depressive symptoms in old age in Germany. By using FE regressions, (1) time-constant heterogeneity can be taken into account, providing unbiased estimates (under the assumption of strict exogeneity). Moreover, (2) insights into the causal relationship can be derived. Furthermore, because individuals were recruited via GP offices and almost every individual in old age has regularly GP visits in Germany, the sample can be considered as nearly representative. Additionally, HRQoL was quantified by using the validated EQ-VAS. Moreover, depressive symptoms was assessed by the well-validated GDS.

However, due to data restrictions, we were not able to distinguish between the different areas of social engagement (e.g. engagement in the church, as a volunteer, in a party, or in a club). There might be some differences in the effect on our outcome variables. Moreover, our estimates might be biased downwards for reasons of panel attrition in the AgeCoDe study.

\section{Conclusion}

Our data underline the importance of social engagement in late life. Thus, encouraging individuals to start, maintain and expand social engagement might help to maintain and improve HRQoL as well as to decrease depressive symptoms in old age. Moreover, social 
engagement in late life may also be beneficial for society as a whole [17]. Future research should disentangle which aspects of social engagement in late life are associated with HRQoL and depressive symptoms to understand more fully the conditions that influence the effect of social engagement on HRQoL and depressive symptoms in late life [17].

\section{Abbreviations}

ACL: Americans' Changing Lives; AgeCoDe: German Study on Ageing, Cognition and Dementia in Primary Care Patients; AIM: Aging in Manitoba; CASMIN: Comparative Analysis of Social Mobility in Industrial Nations; CES-D: Center for Epidemiological Studies Depression Scale; FE: Fixed effects; GDS: Geriatric Depression Scale; GP: General Practitioner; HRQoL: Health-related quality of life; IADL: Instrumental Activities of Daily Living; LSOA: Longitudinal Study on Aging; NH: Nursing home; RE: Random effects; VAS: Visual Analogue Scale

\section{Acknowledgements}

Members of the AgeCoDe Study Group:

Principal Investigators: Wolfgang Maier, Martin Scherer*

Heinz-Harald Abholz, Cadja Bachmann, Horst Bickel, Wolfgang Blank, Hendrik van den Bussche, Sandra Eifflaender-Gorfer, Marion Eisele, Annette Ernst,

Angela Fuchs, André Hajek, Kathrin Heser, Frank Jessen, Hanna Kaduszkiewicz, Teresa Kaufeler, Mirjam Köhler, Hans-Helmut König, Alexander Koppara, Carolin Lange, Hanna Leicht, Tobias Luck, Melanie Luppa, Manfred Mayer, Edelgard Mösch, Julia Olbrich, Michael Pentzek, Jana Prokein, Anna Schumacher, Steffi Riedel-Heller, Janine Stein, Susanne Steinmann, Franziska Tebarth, Michae Wagner, Klaus Weckbecker, Dagmar Weeg, Jochen Werle, Siegfried Weyerer, Birgitt Wiese, Steffen Wolfsgruber, Thomas Zimmermann.

*Hendrik van den Bussche (2002-2011).

We want to thank both all participating patients and their general practitioners for their good collaboration.

\section{Funding}

This publication is part of the German Research Network on Dementia (KND), the German Research Network on Degenerative Dementia (KNDD), and the Study on Needs, Health Service Use, Costs and Health-related Quality of Life in a large Sample of Oldest-old Primary Care Patients (85+) (AgeQualiDe) and was funded by the German Federal Ministry of Education and Research (grants KND 01Gl0102, 01Gl0420, 01GI0422, 01Gl0423, 01Gl0429, 01Gl0431, 01Gl0433 and 01Gl0434; grants KNDD 01Gl0710, 01Gl0711, 01Gl0712, 01Gl0713, 01Gl0714, 01Gl0715, 01Gl0716; and grants AgeQualiDe 01GY1322A, 01GY1322B, 01GY1322C, 01GY1322D, 01GY1322E, 01GY1322F, 01GY1322G). The funder had no role in study design, data collection and analysis, decision to publish, or preparation of the manuscript.

\section{Availability of data and materials}

Due to restrictions that protect participant privacy, data are available upon request. Legal restrictions in form of data guidelines require the central data center to be involved in any handling and distribution of all data. The data will be available upon request to all interested researchers. Interested parties may contact the Working Group Medical Statistics and IT-Infrastructure (contact information: Birgitt Wiese, wiese.birgitt@mh-hannover.de, +49511532-4414).

\section{Authors' contributions}

Study concept and design: AH, CB, TM, AE, SM, SW, JS, TL, HB, MW, KH, WM MS, BW. Acquisition of data: JW, AF, MP, DW. Analysis and interpretation of data: $A H, H H K, S R H, B W, A F, M P, D W$. Preparation of manuscript: $A H, H H K$, $\mathrm{SRH}$. All authors critically revised the manuscript. All authors read and approved the final manuscript.

\section{Ethics approval and consent to participate}

The AgeCoDe-study was conducted in accordance with the Declaration of Helsinki [30] and was approved by the local ethic committees of all participating centers (file reference numbers: Ethics Commission of the Medical Association Hamburg: OB / 08 / 02 \& 2817/2007; Ethics Commission of the University of Bonn: 050/02 \& 174/02 for E 3.2 \& 258/07; Medical Ethics Commission II, University of Heidelberg at the University Medical Center of Mannheim: 0226.4
\& 2002 2007-253E-MA; Ethics Commission at the Medical Center of the University of Leipzig: 143/2002 \& 309/2007; Ethics Commission of the Medical Faculty of the Heinrich-Heine-University Düsseldorf: 2079/2002 \& 2999/2008; Ethics Committee of the TUM School of Medicine, Munich: 713/02 \& 713/02 E). Written informed consent was obtained from all patients. Patient anonymity was preserved.

\section{Consent for publication}

Not applicable.

\section{Competing interests}

The authors declare that they have no competing interests.

\section{Publisher's Note}

Springer Nature remains neutral with regard to jurisdictional claims in published maps and institutional affiliations.

\section{Author details \\ ${ }^{1}$ Department of Health Economics and Health Services Research, Hamburg Center for Health Economics, University Medical Center Hamburg-Eppendorf, Hamburg, Germany. ${ }^{2}$ Department of Primary Medical Care, Center for Psychosocial Medicine, University Medical Center Hamburg-Eppendorf, Hamburg, Germany. Institute of General Practice, Hannover Medical School, Hannover, Germany. ${ }^{4}$ Central Institute of Mental Health, Medical Faculty Mannheim/Heidelberg University, Mannheim, Germany. ${ }^{5}$ nstitute of General Practice, Medical Faculty, Heinrich-Heine-University Düsseldorf, Düsseldorf, Germany. ${ }^{6}$ Institute of Social Medicine, Occupational Health and Public Health, University of Leipzig, Leipzig, Germany. ${ }^{7}$ Department of Psychiatry, Technical University of Munich, Munich, Germany. ${ }^{8}$ Department of Psychiatry, University of Bonn, Bonn, Germany. ${ }^{9}$ German Center for Neurodegenerative Diseases (DZNE), Bonn, Germany.}

Received: 28 February 2017 Accepted: 29 June 2017

Published online: 14 July 2017

\section{References}

1. Bennett KM. Low level social engagement as a precursor of mortality among people in later life. Age Ageing. 2002;31:165-8.

2. Kaplan BH, Cassel JC, Gore S. Social support and health. Med Care. 1977:15:47-58.

3. O'Reilly P. Methodological issues in social support and social network research. Soc Sci Med. 1988;26:863-73.

4. Bennett KM, Morgan K. Health, social functioning, and marital status: stability and change among elderly recently widowed women. Int J Geriatr Psychiatry. 1992;7:813-7.

5. Sabin EP. Social relationships and mortality among the elderly. J Appl Gerontol. 1993:12:44-60.

6. Dathe D: Monitor Engagement (Nr. 4). Wie und wofür engagieren sich ältere Menschen? Berlin: Bundesministerium für Familie, Senioren, Frauen und Jugend; 2011

7. Zunzunegui M-V, Alvarado BE, Del Ser T, Otero A. Social networks, social integration, and social engagement determine cognitive decline in community-dwelling Spanish older adults. J Gerontol Ser B Psychol Sci Soc Sci. 2003:58:S93-S100

8. Heo S, Lennie TA, Okoli C, Moser DK. Quality of life in patients with heart failure: ask the patients. Heart \& Lung:J Acute Crit Care. 2009:38:100-8.

9. Bowling A, Seetai S, Morris R, Ebrahim S. Quality of life among older people with poor functioning. The influence of perceived control over life. Age Ageing. 2007;36:310-5

10. Cheung M, Ting W, Chan L, Ho K, Chan W. Leisure participation and health-related quality of life of community dwelling elders in Hong Kong. Asian J Gerontol Geriatr. 2009;4:15-23.

11. Craigs CL, Twiddy M, Parker SG, West RM. Understanding causal associations between self-rated health and personal relationships in older adults: a review of evidence from longitudinal studies. Arch Gerontol Geriatr. 2014;59:211-26.

12. Menec $\mathrm{VH}$. The relation between everyday activities and successful aging: a 6-year longitudinal study. J Gerontol Ser B Psychol Sci Soc Sci. 2003:58:S74-82.

13. Schwingel A, Niti MM, Tang C, Ng TP. Continued work employment and volunteerism and mental well-being of older adults: Singapore longitudinal ageing studies. Age Ageing. 2009;38:531-7.

14. Hajek A, Brettschneider C, Lange C, Posselt T, Wiese B, Steinmann S, Weyerer S, Werle J, Pentzek M, Fuchs A, et al. Gender differences in the 
effect of social support on health-related quality of life: results of a population-based prospective cohort study in old age in Germany. Qual Life Res. 2016;25:1159-68.

15. Hajek A, König H-H. Informal Caregiving and subjective well-being: evidence of a population-based longitudinal study of older adults in Germany. J Am Med Dir Assoc. 2016;17:300-5.

16. Hong S-I, Hasche L, Bowland S. Structural relationships between social activities and longitudinal trajectories of depression among older adults. The Gerontologist. 2009:49:1-11.

17. Morrow-Howell N, Hinterlong J, Rozario PA, Tang F. Effects of volunteering on the well-being of older adults. J Gerontol Ser B Psychol Sci Soc Sci. 2003;58:S137-45.

18. Herzog A, House JS. Productive activities and aging well. Generations J Am Soc Aging. 1991;15:49-54.

19. Glass TA, Seeman TE, Herzog AR, Kahn R, Berkman LF. Change in productive activity in late adulthood: MacArthur studies of successful aging. J Gerontol Ser B Psychol Sci Soc Sci. 1995:50:S65-76.

20. Sprangers MA, Schwartz CE. Integrating response shift into health-related quality of life research: a theoretical model. Soc Sci Med. 1999:48:1507-15.

21. Luck T, Riedel-Heller SG, Luppa M, Wiese B, Wollny A, Wagner M, Bickel H, Weyerer S, Pentzek M, Haller F, et al. Risk factors for incident mild cognitive impairment-results from the German study on ageing, Cognition and dementia in primary Care patients (AgeCoDe). Acta Psychiatr Scand. 2010;121:260-72

22. Rabin R. Charro F: EQ-5D: a measure of health status from the EuroQo group. Ann Med. 2001;33:337-43.

23. Holland R, Smith RD, Harvey I, Swift L, Lenaghan E. Assessing quality of life in the elderly: a direct comparison of the EQ-5D and AQoL. Health Econ. 2004;13:793-805.

24. Yesavage JA, Sheikh JI. 9/Geriatric depression scale (GDS) recent evidence and development of a shorter violence. Clin Gerontol. 1986;5:165-73.

25. Lesher EL, Berryhill JS. Validation of the Geriatric depression scale-short form among inpatients. J Clin Psychol. 1994;50:256-60.

26. Brauns H, Steinmann S. Educational reform in France, West-Germany, the United Kingdom and Hungary: updating the CASMIN educational classification. ZUMA-Nachr. 1999:44:7-44.

27. Lawton MP, Brody EM. Assessment of older people: self-maintaining and Instrumental activities of daily living. Gerontologist. 1969;9:179-86.

28. Cameron AC, Trivedi PK. Microeconometrics: methods and applications. New York: Cambridge University Press; 2005.

29. Bennett KM. Longitudinal changes in mental and physical health among elderly, recently widowed men. Mortality. 1998;3:265-73.

30. Crespo CJ, Keteyian SJ, Heath GW, Sempos CT. Leisure-time physical activity among US adults: results from the third National Health and nutrition examination survey. Arch Intern Med. 1996;156:93-8.

\section{Submit your next manuscript to BioMed Central and we will help you at every step:}

- We accept pre-submission inquiries

- Our selector tool helps you to find the most relevant journal

- We provide round the clock customer support

- Convenient online submission

- Thorough peer review

- Inclusion in PubMed and all major indexing services

- Maximum visibility for your research

Submit your manuscript at www.biomedcentral.com/submit

CBiomed Central 